\title{
LÍQUEN PLANO EROSIVO - POTENCIAL DE MALIGNIZAÇÃO E RELATO DE CASO
}

Lino Oliveira Carvalho de SANTANA, Felipe Belmonte ARCHETTI, Ana Paula Ribeiro BRAOS

O líquen plano oral (LPO) é uma doença mucocutânea inflamatória crônica cuja etiopatogenia permanece indefinida. Várias formas clínicas do LPO foram descritas, mas atualmente são classificadas como reticulares e atrófico-erosivas com áreas eritematosas e ulceradas e sensibilidade dolorosa. O tratamento do LPO é feito com corticosteroides associados ou não com outras terapias. Há relatos e controvérsias na literatura quanto ao potencial de malignidade do LPO. O objetivo deste estudo foi apresentar um caso clínico de LPO erosivo e a abordagem terapêutica, além de revisão da literatura quanto ao potencial de malignidade. Paciente gênero masculino, 37 anos, leucoderma, com queixa de dor e queimação na boca. Ao exame intrabucal, observaram-se áreas reticulares e eritematoso-ulcerativas em toda a mucosa jugal e gengiva inserida. Após biópsia incisional, o resultado histopatológico foi compatível com o exame clínico. O paciente foi medicado com corticosteroides tópico e sistêmico com melhora significativa em uma semana de tratamento. A lesão apresenta melhoras, com pouca sensibilidade dolorosa. O paciente está em acompanhamento devido à etiologia erosiva da lesão. Com este quadro, podese concluir que casos de estomatodermatopatologias com caráter autoimune necessitam de diagnóstico rápido e abordagem terapêutica multiprofissional, para que a doença e sintomatologia sejam controladas.

Palavras-chave: Líquen plano; Reação auto-imune; Manifestações bucais. 